\title{
A Proposal for Social Pricing of Water Supply in Côte
}

\author{
d'Ivoire*
}

\author{
Daouda DIAKITE† Aggey SEMENOV ${ }^{\ddagger}$ and Alban THOMAS ${ }^{\S}$
}

February 2008

\begin{abstract}
We consider the design of a nonlinear social tariff for residential water in Côte d'Ivoire, which is a case of a monopolistic private operator supplying a population of heterogeneous consumers. The proposed optimal tariff includes an initial "social" block with a low unit price, and higher consumption blocks with a monopoly pricing rule. This optimal nonlinear tariff is calibrated using econometric estimates of a paneldata residential water demand equation. Welfare changes associated with moving from the actual tariff to approximations of the optimal pricing system are computed under different tariff scenarios. We find that gains in consumer welfare would outweigh losses in producer surplus in a majority of Ivorian local communities.
\end{abstract}

Keys Words : Multiblock tariff, Social Pricing, Residential Water Supply.

JEL classification codes: C33, I38, O13, Q25.

* We are grateful to Mark Rosenzweig (the Editor), four anonymous referees, Robert Wilson and Michael Hanemann for helpful comments.

${ }^{\dagger}$ Toulouse School of Economics, LERNA.

${ }^{\ddagger}$ National University of Singapore.

${ }^{\S}$ Corresponding author. Toulouse School of Economics, INRA, LERNA. 21 Allée de Brienne, F-31000 Toulouse, France. email thomas@toulouse.inra.fr 


\section{Introduction}

Over the past 20 years, the world's residential water consumption has increased at a much higher rate than that of population. The international community has become progressively aware of the role played by access to safe drinking water and sewage in economic development. Indeed, the vast majority of households without such access are in developing countries, where the problem often does not lie with the scarcity of water, but with the difficulty to finance water supply and treatment operations. Investments in the water industry are typically long-term, due to large infrastructure costs associated with redesigning or building water networks.

As governments in developing countries find it challenging to fund these investment requirements, an alternative is to promote public-private partnerships or concession contracts in the water industry. Resorting to private companies to invest and operate water utilities does not mean that the objectives of the local communities and the State regarding environmental protection and consumers' welfare will be neglected. As it stands, private companies operating in developing countries face difficulties in meeting their financial objectives, because a fraction of the consumers fail to pay their water bills. Majority of customers are typically able to pay their daily water residential consumption as the marginal water prices are generally low. However, for operators, fixed costs make a significant share of water bills and often lead to difficulties in cost recovery. ${ }^{1}$

One of the possibilities to facilitate water access to poor households is to design an income-targeted subsidy policy. Under such a system, a household, after being identified as "poor", pays only a fraction of the full water bill or part of the fixed fee (i.e., the lumpsum payment corresponding to the connection fee). The operator is then compensated by a transfer from the local community, or from the federal or regional compensation schemes. Another possibility is to base the subsidy policy on volumes consumed only. In this case, a multi-part block rate tariff is designed, with a minimum water consumption level supplied

\footnotetext{
${ }^{1}$ This is particularly true for some countries in Central America and Africa (see Strand and Walker, 2005; Collignon et al., 2000).
} 
at zero or very low price. The losses for the operator are compensated from the higher consumption blocks and/or from other customer categories, for instance, the industries. Such initiatives, called "social pricing", are followed in various regions around the world, and have shown that different solutions require careful adjustments to suit local population needs. Social tariff schemes rely on several tariff components as instruments for modifying the households' behavior, in particular the structure of the consumption blocks and their associated unit prices, and/or the fixed part of the tariff. From a theoretical point of view, the optimal social pricing scheme should take into account consumers' preferences for water consumption along with the preferences of the regulator. The latter is assumed to maximize consumer welfare while ensuring a profitable operation for the private company in charge of the water network.

In this paper we suggest a simple social tariff structure for a monopolistic operator supplying a population of income-diverse consumers. The optimal pricing rule is obtained as the solution to a special case of the general Ramsey pricing problem presented in Wilson (1993). Under the Ramsey pricing model, the initial level of consumption is charged at a fixed rate, up to a level with is determined by the parameters of the model. While Wilson (1993) interprets this multi-part tariff in the context of fixed fee (access fee for instance), in our case the first pricing block of the tariff originates from the social objective of the regulator.

The contribution of the present paper to the literature on nonlinear pricing does not lie in the construction of a new framework for designing optimal tariffs for public services, rather, by using Wilson's (1993) theoretical framework of nonlinear pricing, we propose a method for calibrating and approximating (by multi-block price systems) optimal tariffs that include social considerations.

The water industry in Côte d'Ivoire presents an interestring case for several reasons. First, a common rate policy for every local community of the country is implemented by the (sole) water operator SODECI (Société de Distribution d'Eau de Côte d'Ivoire, established in 1956). Second, poor customers actually benefit from subsidized connection charges, as 
well as from a reduced-rate initial consumption block. Third, the existing tariff is of the increasing-block type, which means that higher-income customers would also benefit from the reduced-rate in the initial consumption block.

By comparing the optimal nonlinear tariff with the existing tariff in Côte d'Ivoire, we determine whether an increase in social welfare could be achieved by modifying the number of consumption blocks, their threshold levels and unit prices. In particular, we examine the impact on social welfare of increasing the number of block rates. To this end, we replace our optimal pricing system with a series of multiple-rate tariff approximations, that are simplified for the sake of clarity. Although this comes at the cost of losing optimality properties of the tariff, such approximations are more in line with the apparent features of the existing tariffs. We also examine the impact on social welfare of imposing a water tariff that has the increasing block structure, although the optimal pricing rule is not monotonic in water volumes.

The paper is organized as follows. Section 2 discusses water pricing and describes the existing pricing scheme in Côte d'Ivoire. Section 3 presents a theoretical motivation for nonlinear social pricing. Section 4 presents an empirical application to Côte d'Ivoire. The results from the simulation experiment are given in Section 5, and a comparison is made with the existing water tariff scheme in Côte d'Ivoire. We consider several approximations to the optimal water tariff by imposing an increasing block rate tariff structure and by letting the number of pricing blocks vary. Section 6 concludes.

\section{Water pricing}

\subsection{Pricing rules for water utilities}

Whether publicly or privately operated, water utilities are generally considered natural monopolies because of declining long-run average costs, and high fixed costs relative to variable costs. Designing an efficient water pricing policy is crucial for water companies in local communities. A price policy is often a compromise between various (and possibly conflicting) 
objectives: economic efficiency, cost recovery, equity, and resource conservation.

The first objective of a water utility pricing scheme is to generate revenues covering at least the operating (short-run) costs. Without regulation, a monopoly maximizes profit so that the marginal cost is equal to the marginal revenue. By doing so however, consumers' surplus is minimized which results in a socially suboptimal tariff. If the monopoly is regulated by an utilitarian social planner, maximizing the social welfare leads to the marginal cost pricing rule (MCP) and thus, satisfying the economic efficiency objective. If price does not reflect the social marginal cost, consumers do not receive appropriate information about the societal cost of a marginal increase in demand (Renzetti and Kushner, 2004). MCP has received a criticism on the account of absence of a budget constraint, deficit if the firm operates under increasing returns to scale, etc. Further, it has given rise to a number of practical difficulties (Boland and Whittington, 2000). Also, from an equity point of view, MCP collects too much revenue if the marginal cost is above the average cost. For these reasons, there is little evidence of real-world applications of MCP in water utilities (Renzetti, 2000).

An alternative solution is to use a two-part tariff with a marginal price corresponding to the marginal cost and a fixed charge allowing for the deficit recovery. However, this system is often seen as regressive as the high connection fee constitutes a significant proportion of the total bill for low-volume consumers (and therefore, a significant proportion of the average water price). ${ }^{2}$ If the water managers are concerned with the distributional consequences of the tariff, then a preferred policy is to set the unit charge above the marginal cost, so as to reduce the fixed part of the tariff. Renzetti (2000) shows that such a policy (also called the Feldstein pricing) is clearly suboptimal in a wide range of cases as the unit rates are significantly distorted from the marginal cost.

A natural extension of the two-part tariff is the class of block rate pricing systems, the Increasing Block Rate (IBR) or the Decreasing Block Rate (DBR), in which the number

\footnotetext{
${ }^{2}$ Average price in the two-part tariff is equal to the marginal price plus the fixed charge divided by the consumption volume.
} 
of blocks is greater than two. ${ }^{3}$ Increasing or decreasing block rate pricing can solve the problem of excess profits and losses generated by the marginal pricing in cases of economies and diseconomies of scale respectively. One drawback of the block rate pricing is that it makes the revenue of the water utility more variable as consumers, by changing their water consumption may switch from one price block to another. Nowadays, the use of the IBR systems is widespread in developing countries (Boland and Whittington, 2000), their success lies in the objectives they are claimed to achieve: the equity objective by subsidizing small (presumably poor) customers by charging bigger customers, the resource conservation objective, the promotion of economic efficiency through the marginal cost pricing for the highest block. However, the IBR pricing may be in contradiction with the basic principles of monopoly pricing. It may even lead to social losses when the block rates are not designed to preserve the interests of the water operator and large consumers. Some water companies use more complex pricing schemes that combine both the increasing and the decreasing block structures. The marginal price can increase in the first block and then decrease to favor both very small and very large water consumers.

In a second-best world, where the budget constraint of the water utility is introduced, the pricing system involves the Ramsey-Boiteux rule (see, e.g., Laffont and Tirole, 2000; Prieger, 1996; Baumol, 1987). In this case, the gap between the marginal price and the marginal cost depends on the price elasticity of water demand and the cost of the budget constraint, and this pricing rule ensures the highest social welfare under a budget constraint. In practice, implementing this policy requires perfect knowledge of the production cost and consumer demand function for a private monopoly, and of the consumer demand function for a public monopoly.

Extensions of the single price models such as the MCP or the Ramsey-Boiteux pricing involve a nonlinear pricing schedule (Brown and Sibley, 1986; Wilson, 1993), for a welfaremaximizing public utility faced with a set of income-diverse consumers. Consumers vary

\footnotetext{
${ }^{3}$ Boland and Whitthington (2000) proposed a uniform price with rebate as an alternative to a two-part tariff.
} 
according to their "type" which is represented by an unobservable parameter $\theta$ (e.g., the price sensitivity of demand, income). The price schedule is a nonlinear function of quantity (either increasing or decreasing in the consumption level), and depends on both supply and demand parameters (in particular, the utility's marginal cost and the distribution of $\theta$ ). The practical implementation of an optimal nonlinear pricing rule involves the use of an approximation by blocks, for instance, using the IBR system. In this case, the nonlinear price formula is discretized into a number of blocks, so as to mimic the original nonlinear pricing rule. A way to reduce the loss in optimality due to approximation is to consider a large number of blocks in the tariff.

\subsection{Water pricing in Côte d'Ivoire}

In Côte d'Ivoire, the water supply sector is divided into two subsectors: urban water supply systems (named "hydraulique urbaine") and rural water supply (named "hydraulique villageoise"). This distinction is based on technical network and connection parameters, investments, financing and operating modes, and the type of population supplied. For example, a water supply system is considered urban if the local community's population is above 3000 inhabitants, if a water distribution network exists, etc. ${ }^{4}$

Since the 1987 delegation contract, the concession of SODECI - the largest water operator in the country, caters only to communities in the urban water supply systems. Other communities - according to criteria mentioned above - are supplied by the rural water systems, which could be either traditional (hand-pumps) or improved systems (water towers and standpipes).

As in most countries in Western Africa, SODECI uses an IBR pricing scheme. The water tariff includes a value added tax and two special taxes for financing the Fonds National de l'eau (FNE, National Water Fund) and the Fonds de Développement (FDE, Development Fund for Water) respectively. The FDE is devoted to financing "social" (subsidized) network connections, hydraulic facility replacement costs, network extension operations and invest-

\footnotetext{
${ }^{4}$ See Direction de l'Hydraulique Humaine (2001) for a description of these criteria.
} 
ments in new facilities and equipment; while the FNE is concerned with the contract-related loans in the water sector.

The price components to be used by SODECI are specified in the 1987 contract and a price revision should occur every 5 years according to the contract. In fact, the price structure has experienced a series of modifications over the period 1996-2005.

The first block, called "forfait" (set price), concerns volumes below $36 \mathrm{~m}^{3} /$ year, where households pay a fixed fee of 16.07 USD/year. ${ }^{5}$ The second block, called "social", is for volumes between 36 and $76 \mathrm{~m}^{3} /$ year and has a unit price of $0.50 \mathrm{USD} / \mathrm{m}^{3}$. The third block, called "domestic", is for volumes between 76 and $364 \mathrm{~m}^{3} /$ year and has a flat rate of 0.79 USD $/ \mathrm{m}^{3}$. The final block, denoted "standard", concerns volumes above $364 \mathrm{~m}^{3} /$ year and is associated with a unit price of $1.26 \mathrm{USD} / \mathrm{m}^{3}$. The average annual household consumption is around $120 \mathrm{~m}^{3}$, therefore a significant proportion of the total volumes consumed by households is expected to lie within the third block. Finally, note that the "social" block ${ }^{6}$ more or less follows standard recommendations in terms of basic needs, namely a minimum requirement of $76 \mathrm{~m}^{3} /$ year corresponding to a 5 -person household (see Gleick, 1996). ${ }^{7}$

In order to increase the supply of residential drinking water, the authority in charge of urban water services had formulated an ambitious policy of subsidized residential water connections in the mid 1980s. The subsidy was granted to $15 \mathrm{~mm}$-diameter water pipe connections (this was done to limit the available volume for the household requirements) within a 12 meter limit from the main connection pipe to the water meter (in the public domain). Above this limit, any additional pipe connection cost as well as the costs of the appliances after the meter were borne by the residential customer. The policy benefited customers from a lower connection cost of 36.68 USD instead of 359 USD for a usual connection. SODECI

\footnotetext{
${ }^{5}$ In this paper, monetary amounts are expressed in US Dollars. 1 USD is about 656 FCFA (monetary unit of the African French-Speaking Financial Community).

${ }^{6}$ The social block included the "forfait" block. Note that the first and second block have the same unit price of 0.44 USD per $\mathrm{m}^{3}$. The first block was designed to take into account very small users.

${ }^{7}$ In Côte d'Ivoire, households have on average 6.5 members. The minimum individual requirement is 15 $m^{3} /$ year.
} 
did all the necessary connection work and it was reimbursed for the uniform subsidy (190 USD) by the FDE. The difference from the usual connection cost could be explained by a tax exemption on subsidized connections, and a reduced mark-up for SODECI. The materials and components for subsidized connections were exempted from VAT and customs duties. ${ }^{8}$ The subsidy policy implemented in Côte d'Ivoire helped to address the issues raised by the fixed fee. Once connected to the network, users were only charged the variable component of the tariff, and did not have to pay the fixed fee. There were specific criteria for targeting the access to subsidized connections, however they were fairly limited. The connection could only be for residential use, not for commercial purposes; and it could not be used for re-selling water volumes. Furthermore, it must not be associated with more than 4 water taps. The following "standing" criterion was decided in 1998 to limit access to "low-income" households only. In order for a household (represented by a customer to the company) to obtain such a connection, it must supply a property title if it owns a house, or for a tenant, a renting lease agreement. Moreover, connections for public work (where the control of the number of taps was not possible) and connections for real estate operations were excluded from the scope of the policy. The objective of promoting a wider access to drinking water for the population has been translated in practice by the fulfillment of all demands corresponding to the eligibility criteria discussed above. Therefore, between 1986 and 1998, 286,853 new water network connections had been installed. Out of the total new connections, 261,019 were subsidized connections and. ${ }^{9}$ That is, 91 percent of new connections were subsidized (87 percent in Abidjan and 95 percent in other regions).

Overall, the subsidized connection policy led to a sharp increase in the number of customers (87 percent growth between 1987 and 1997). The success of the policy rested on the financial strength and adequate management of the FDE. The capacity of the fund to finance the policy ultimately depended on the relative number of new customers over the existing ones. In 2002, the government was forced to revise the eligibility criteria, so as to reduce the number of admissible households. Under the revised criteria, the maximum number of

\footnotetext{
${ }^{8}$ The standard connection cost before VAT was 237.71 USD.

${ }^{9}$ These figures correspond to all categories of users and diameter types.
} 
water taps associated with the residential connection must not exceed 3. Furthermore, a single connection could only be made in a housing unit, and the total number of subsidized connections every year could not exceed 10,000 for the whole country.

\section{$3 \quad$ Nonlinear social pricing}

In this section, we introduce the basic setup for designing a social pricing system. The optimal pricing rule is obtained as the solution to a special case of the general Ramsey pricing problem presented in Wilson (1993). To account for income effect in the tariff design we use the generalized demand profile (see also Brown and Sibley, 1986) to describe consumer behavior and to determine the optimal pricing scheme. ${ }^{10}$

According to the Ramsey principle, we consider an optimal nonlinear pricing system as the solution to the social planner problem which includes the producer's profit and the consumers' surplus. We explicitly include in the problem an initial consumption block (although its rate may not be necessarily lower than rates in the subsequent blocks). The derived pricing formula is called "social pricing" because of the restriction that a minimum volume be supplied at the lowest price possible.

We consider the water market in the context of partial equilibrium analysis. From the supply side water is supplied by a monopolistic firm, with cost function $C(q)$, and a marginal cost denoted by $c(q)$. The demand side of the market is represented by a set of heterogenous consumers. The heterogeneity in consumer preferences is captured by a single parameter $\theta \in[\underline{\theta}, \bar{\theta}]$ which we associate with the household income. An implicit assumption underlying the model is that water demand is increasing in income. Each household can then be described by its individual demand function

$$
q=q(p, \theta)
$$

where $q$ and $p$ denote the household's water consumption in $m^{3}$ and the marginal price

\footnotetext{
${ }^{10}$ However, we restrict the set of possible tariffs in order to make them tractable and applicable for estimation.
} 
(in $\left.U S D / m^{3}\right)$ respectively. We assume that demand curves do not cross, that is, $q(p, \theta)$ is monotonic in $\theta$ for any price $p$. We also assume that the social planner has knowledge on the distribution of types (income) in the population, as well as the production technology (the cost function) and the consumers' demand functions.

The benefit for the consumer with type $\theta$ from the purchase of $q$ units is $U(q, \theta)$, and thus, $U(q, \theta)$ also represents the consumer's maximum willingness to pay for these $q$ units. Let $v(q, \theta)$ denote the willingness to pay for the consumer of type $\theta$ for a $q$-th unit increment in consumption. $v(q, \theta)$ is then the marginal benefit, $v(q, \theta)=\partial U(q, \theta) / \partial q \cdot{ }^{11}$

Define the total tariff as

$$
P=T+p(q, \theta) \times q(p, \theta),
$$

where $T$ (in $U S D$ ) is the fixed part of the tariff, and $p(q, \theta)$ is the marginal price associated with consumption of $q$ units.

The key ingredient of the demand-profile approach is the generalized demand function $Q(P, p, q)$, defined as the number of customers (length in case of an interval) who are willing to pay the total fee $P(q)$ (in $U S D$ ) for the purchase of $q$ units of water, and are also willing to pay $p$ for the $q$ th marginal unit:

$$
Q=Q(P, p, q)=\operatorname{card}\{\theta \mid U(q, \theta) \geq P \text { and } v(q, \theta) \geq p\} .
$$

Another useful interpretation of the generalized demand function is the following: $Q(P, p, q)$ is a measure of the set of customers who are willing to pay the total tariff $P$ and are ready to buy more than $q$ units $\left(m^{3}\right)$ at price $p: Q(P, p, q)=\operatorname{card}\{\theta \mid U(q, \theta) \geq P$ and $q(p, \theta) \geq q\}$.

The social planner plays the role of the principal who maximizes social welfare subject to the social goals. The objective of the principal is to maximize the sum of consumers' and producer surpluses in the water market. The strategy of the principal translates into a function of total tariffs $P(q)$ or, equivalently, into a marginal price schedule $p(q)=P^{\prime}(q)$, such that it maximizes social welfare. The households then choose the volume $q$ and pay the total tariff $P(q)$.

\footnotetext{
${ }^{11}$ It can also be interpreted as the inverse demand function $p(q, \theta)=v(q, \theta)$.
} 
We consider the income effect in the tariff design in a simplest way possible. The social planner imposes the restriction that a minimum amount of water be supplied at the lowest marginal price possible. To account for this restriction, we introduce a minimum quantity, $q_{\min }\left(\right.$ in $m^{3}$ ), below which customers will only pay a fixed fee $P_{\min }$ (in $U S D$ ) and the marginal price is set equal to zero. Since $T$ is the fixed fee that consumers are ready to pay given that the marginal price is zero, the surplus for consumers who buy the minimal amount of water is $\int_{\infty}^{P_{\min }}\left[T-P_{\min }\right] d Q\left(T, 0, q_{\min }\right)$ and integrating by parts yields $\int_{P_{\min }}^{\infty} Q\left(T, 0, q_{\min }\right) d T .{ }^{12}$ The consumers' surplus from the $q$ th $m^{3}$ for other consumers is $\widetilde{Q}(P(q), p(q), q)=\int_{\infty}^{p(q)}[s-p(q)] d Q(P(q), s, q)$. Again after integration by parts we have $\widetilde{Q}(P(q), p(q), q)=\int_{p(q)}^{\infty} Q(P(q), s, q) d s$. Denote $q_{\max }$ as the maximum allowed volume of water. ${ }^{13}$ Then the consumer surplus for consumers who purchase the quantity $q \in\left[q_{\min }, q_{\max }\right]$ is $\int_{q_{\min }}^{q_{\max }} \widetilde{Q}(P(q), p(q), q) d q$. The total consumer surplus is therefore:

$$
C S=\int_{P_{\min }}^{\infty} Q\left(T, 0, q_{\min }\right) d T+\int_{q_{\min }}^{q_{\max }} \widetilde{Q}(P(q), p(q), q) d q .
$$

The firm's receipts from the $Q\left(P_{\text {min }}, 0, q_{\text {min }}\right)$ poor customers consist only of the fixed fee $P_{\min }$. The profit margin for the $q$ th unit, where $q \in\left[q_{\min }, q_{\max }\right]$, is $[p(q)-c(q)]$ and it comes from the $Q(P(q), p(q), q)$ customers who are willing to pay the total fee $P(q)$ and marginal price $p(q)$. The producer surplus is then:

$$
P S=Q\left(P_{\min }, 0, q_{\min }\right)\left[P_{\min }-C\left(q_{\min }\right)\right]+\int_{q_{\min }}^{q_{\max }} Q(P(q), p(q), q)[p(q)-c(q)] d q .
$$

The first term is the profit coming from the poor consumers who are subject to the social pricing, and the second term comes from the remaining consumers' continuum. Denote $\lambda>0$ as the opportunity cost of public funds. ${ }^{14}$ The principal's objective is now to solve the following problem:

$$
\underset{p(q), q_{\min }, P_{\min }}{\operatorname{Max}} \int_{P_{\min }}^{\infty} Q\left(T, 0, q_{\min }\right) d T+\int_{q_{\min }}^{q_{\max }} \widetilde{Q}(P(q), p(q), q) d q+
$$

\footnotetext{
${ }^{12}$ Since $Q\left(T, 0, q_{\text {min }}\right)$ is a decreasing function of $T$ the limits in the first integral are taken backwards.

${ }^{13}$ In Côte d'Ivoire it is exogenously fixed for households at $1200 \mathrm{~m}^{3} /$ year/household. All volumes beyond this level are charged at the industrial tariff.

${ }^{14}$ See Laffont and Tirole (1993).
} 


$$
(1+\lambda)\left[Q\left(P_{\min }, 0, q_{\min }\right)\left[P_{\min }-C\left(q_{\min }\right)\right]+\int_{q_{\min }}^{q_{\max }} Q(P(q), p(q), q)[p(q)-c(q)] d q\right] .
$$

Let $\alpha=\frac{\lambda}{1+\lambda}$ denote the Ramsey number. The optimality conditions for problem (4) are divided into two parts. First, on the interval $\left[0, q_{\min }\right]$, consumers pay only the fixed fee $P_{\min }$. Optimizing (4) with respect to $q_{\min }, P_{\min }$ the values of $q_{\min }, p_{\min }$ and $P_{\min }$ are determined by the elasticity conditions and the transversality condition:

$$
\begin{gathered}
\frac{p_{\text {min }}-c\left(q_{\text {min }}\right)}{p_{\text {min }}}=-\frac{\alpha}{p_{\min }} \frac{Q\left(P_{\text {min }}, 0, q_{\text {min }}\right)}{\frac{\partial}{\partial p} Q\left(P_{\text {min }}, 0, q_{\text {min }}\right)}=\frac{\alpha}{\varepsilon_{p}^{Q}}, \\
\frac{P_{\text {min }}-C\left(q_{\text {min }}\right)}{P_{\text {min }}}=-\frac{\alpha}{P_{\text {min }}} \frac{Q\left(P_{\text {min }}, 0, q_{\text {min }}\right)}{\frac{\partial}{\partial P} Q\left(P_{\text {min }}, 0, q_{\text {min }}\right)}=\frac{\alpha}{\varepsilon_{T}^{Q}}, \text { and } \\
Q\left(T_{\text {min }}, \bar{P}, q_{\text {min }}\right)=Q\left(P\left(p_{\text {min }}, q_{\text {min }}\right), p_{\text {min }}, q_{\text {min }}\right),
\end{gathered}
$$

where $\bar{P}=P_{\min } / q_{\min }$ is the equivalent uniform price derived from the fixed fee $P_{\min }$. The transversality condition (7) implies that $\bar{P}=p_{\min }$; and reflects the fact that households that are willing to pay for the minimum quantity are also ready to pay the marginal price $p_{\min }$ for the additional unit above $q_{\min } .{ }^{15}$ Equation $(5)$ is a monopoly mark-up pricing rule which is essentially the Ramsey pricing rule for the generalized demand function; that is, the product of the percentage profit margin and the price elasticity of generalized demand function should be equal to the Ramsey number. Equation (6) states that the product of the percentage of total profit and the total price elasticity is also equal to the Ramsey number.

Second, in order to simplify the analysis we assume that the benefits of consumers who want to consume more than $q_{\min }$ are sufficiently large such that they are ready to pay a fixed fee $P_{\min }{ }^{16}$ Then for larger purchases, the demand behavior is determined only by the marginal considerations. Thus, the point-wise maximization of (4) with respect to $p(q)$ in the interval $\left[q_{\min }, q_{\max }\right]$ leads to the standard monopoly prices which are given by the Ramsey rule for the ordinary demand:

$$
\frac{p(q)-c(q)}{p(q)}=-\frac{\alpha}{\varepsilon_{p}^{q}(q)}
$$

\footnotetext{
${ }^{15}$ The minimum marginal price $p_{\min }$ is not included in the actual price system. It is used as an useful device for calculating the minimum quantity $q_{\text {min }}$ and the minimum fixed fee $P_{\text {min }}$.

${ }^{16}$ The income effect is taken into account in the model, through the fixed fee.
} 
where $\varepsilon_{p}^{q}(q)$ is the household-level price elasticity of demand.

To summarize, the structure of the water tariff is the following: up to the threshold of $q_{\text {min }}$, there is a flat rate which satisfies the demand of poor consumers, the ones with the lowest values of $\theta$. For quantities greater than $q_{m i n}$, there is a standard monopoly pricing determined by the solution to the problem (4).

\section{Empirical application}

This section is devoted to the estimation of structural demand parameters that will be used to calibrate the optimal pricing model of the previous section. To match the empirical application with the theoretical pricing model, we identify the agent's type $\theta$ by the household income, given the implicit assumption that water demand is (monotonically) increasing in this variable.

As far as the water sector in Côte d'Ivoire is concerned, we need to account for the actual multi-block pricing scheme when estimating price and income elasticities. Until fairly recently, the explicit behavior of households facing a multi-block water pricing system was not analyzed from an econometric viewpoint. A pioneering work is by Hewitt and Hanemann (1995), who use the two-stage model initially proposed by Burtless and Hausman (1978) and Moffitt $(1986,1990) .{ }^{17}$ Hewitt and Hanemann model residential water demand in two stages: first, households choose their consumption block, and in the second step, they maximize their total utility with respect to the budget constraint. The first stage of the model employs discrete choice modeling techniques to estimate the probability that the household consumption lies within a given pricing block. Other applications include Shefter and David (1985), Corral et al. (1998) and Martinez-Espiñeira (2003). Shefter and David (1985), though they make assumptions on the household distribution among the blocks, did not make explicit the method used to obtain the proportion of customers in each block. Corral et al. (1998) and Martinez-Espiñeira (2003) use real time-series data in their estimation,

\footnotetext{
${ }^{17}$ See also Chicoine et al. (1986).
} 
but the data were available for a limited number of local communities only. In practice, when working with aggregate data at the municipality level, the number of customers in the different pricing blocks is rarely available for each community. Since the water tariff in Côte d'Ivoire is of the multi-block type, we will largely use the estimation techniques for such pricing described in the last two studies mentioned above.

The data are collected directly from SODECI, for 156 local communities over the years 1998-2002, the total number of observations in the panel is 780 . These communities are selected because they are already connected to the SODECI water network before $1998 .{ }^{18}$

In each local community, the pricing scheme is the same, with three blocks associated with three different marginal prices ${ }^{19}$. Table 1 presents descriptive statistics for the average water consumption (per household), block shares $s$, average price over the three pricing blocks, and household income. We can see that block 2 accounts for more than 50 percent of the total water consumption, whereas block 3 has a low number of customers on average (8 percent). We also report statistics for demand and block-choice explanatory variables: $I$ (income, in million FCFA), UNPAID (unpaid volumes per household in $m^{3}$ ), PUNPAID (proportion of unpaid volumes, that is, unpaid volumes divided by total water volume billed to customers), NEWSUB (proportion of subsidized new customers), RETURN (water network rate of return), CUST (number of connections in the local community), and ACCESS (access to water in 1000 individuals, CUST multiplied by the size of the household).

\section{[TABLE 1 ABOUT HERE]}

As shown in Corral et al. (1998), the estimating equation for water demand at the community level is:

$$
q_{j t}=\beta_{0}+\beta_{1}\left(\sum_{i=1}^{m} s_{i j t} p_{i j t}\right)+\beta_{2}\left(\sum_{i=1}^{m} s_{i j t}\left(I_{j t}-d_{i j}\right)\right)+\delta Z_{j t}+\varepsilon_{j t},
$$

\footnotetext{
${ }^{18}$ For these communities, database are available from SODECI and Direction de l'hydraulique humaine (the regulation authority of the sector). For other communities not included in the SODECI supply area, there is no water operator and a village committee directly manages the system. So the data are not available for such communities (and additional data collection would require a field survey).

${ }^{19}$ See the discussion on the SODECI water tariff in section 2.3.
} 
where $q_{j t}$ is the representative household demand in community $j$ and period $t$ (in $m^{3}$ ), $m$ is the number of pricing blocks, $s_{i j t}$ is the proportion of customers in the pricing block $i, p_{i j t}$ is the marginal price of water in block $i, I_{j t}$ is the average household income in community $j$, and $d_{i j}$ is the difference variable. ${ }^{20} Z_{j t}$ is a vector of demand shifters and $\varepsilon_{j t}$ is the error term.

The first practical difficulty in estimating equation (9) is that the average price over the blocks, $\sum_{i=1}^{m} s_{i j t} p_{i j t}$, is likely to be endogenous as it depends on the proportion of households in each pricing block. A second difficulty arises from the fact that proportions of households in each block are not observed, although the proportions of total water volumes sold in each block are observed. To deal with the first problem, we use an Instrumental Variable estimation procedure. As for the second problem, we make a simplifying assumption (as explained below) to use observed water volume proportions instead of the proportions of households in each pricing block.

We specify a Logit representation for the block choice $(i)$ of the representative consumer in the community $(j)$ :

$$
\begin{gathered}
\operatorname{Prob}(j \text { chooses block } i \text { at time } t)=\frac{\exp \left(X_{i j t} \beta\right)}{1+\sum_{k=2}^{3} \exp \left(X_{i k t} \beta\right)}, j=2,3, \\
\operatorname{Prob}(j \text { chooses block } 1 \text { at time } t)=\frac{1}{1+\sum_{k=2}^{3} \exp \left(X_{i k t} \beta\right)},
\end{gathered}
$$

where $X_{i j t}$ is the vector of explanatory variables for the block choice. Without loss of generality block 1 is chosen as the reference, such that $\exp \left(X_{1 j t} \beta\right)=1$.

Approximating the probability above by the proportion of households in block $i$ for the local community $j$ at time $t$, denoted by $s_{i j t}$, we have

$$
\log \left(\frac{s_{i j t}}{s_{1 j t}}\right)=X_{i j t} \beta+\varepsilon_{i j t}, \quad i=2,3,
$$

where $\varepsilon_{i j t}$ is a zero-mean disturbance. Because proportions of households in each block are not observed, we assume that the ratio of (billed) water volume proportions in any given

\footnotetext{
${ }^{20}$ The variable difference $d_{i}$ is defined as (see Corral et al., 1998; Nordin, 1976) :

$d_{i}=\sum_{j=1}^{i-1}\left(p_{j}-p_{j+1}\right) \bar{x}_{j}, \quad i=2, \ldots, m$, and $d_{1}=0$, where $p_{j}$ is the marginal price, $\bar{x}_{j}$ is the upper bound of block $j$, and hence, the lower bound of block $j+1$.
} 
pair of blocks is proportional to the ratio of households proportions in that pair of blocks:

$$
\frac{s_{i j t}}{s_{1 j t}}=\gamma_{i j} \times \frac{V_{i j t}}{V_{1 j t}}
$$

where $\gamma_{i j}$ does not depend on time and $V_{i j t}$ are total water sales for block $i$ in community $j$ at time $t$. The relevance of such a proportionality assumption may be disputed, however it is necessary to make this assumption for our empirical purposes. ${ }^{21}$ The final system of equations to be estimated is

$$
\log \left(\frac{V_{i j t}}{V_{1 j t}}\right)=\log \left(\frac{s_{i j t}}{s_{1 j t}}\right)-\log \left(\gamma_{i j}\right)=X_{i j t} \beta+\eta_{i j}+\varepsilon_{i j t}, \quad i=2,3,
$$

where $\eta_{i j}$ is a block- and community-specific effect including $\log \left(\gamma_{i j}\right)$, the proportionality factor between the ratio of consumers in block $i$ relative to block 1 and the ratio of water volumes in the same pair of blocks.

We first estimate the system of the block-choice equations (13) by the Three-Stage Least Squares including fixed effects to eliminate any correlation between the unobserved community-specific heterogeneity and explanatory variables. The instruments used in both equations are average household income, relative prices $p_{3} / p_{1}$ and $p_{2} / p_{1}$, the proportion of unpaid water volumes and the proportion of subsidized customers in the local community. These last two variables are also used as covariates in the block-choice equations. We restrict the parameters associated with price and unpaid volumes to be equal in both equations, so as to be consistent with the (conditional) Logit specification. Results are presented in Table 2. The income effect in the block-2 choice equation is significant and lower than the effect in the block-3 case which turns out to be insignificant. The negative estimated coefficients on PUNPAID and NEWSUB indicate that, on average, local communities characterized with a higher proportion of unpaid water volumes and poor customers have a lower proportion of the total water consumption in higher blocks relative to block 1 . Those two variables are likely to be related to the income and housing characteristics, and hence to be correlated with $I$ through a community-specific fixed effect, which is eliminated by the fixed effects

\footnotetext{
${ }^{21}$ See Diakité, D. and A. Thomas (2005a) for more details about this block share estimation.
} 
procedure. The price coefficient is highly significant and is of the expected sign, indicating that the relative prices increase the probability of households being in the lower consumption block.

\section{[TABLE 2 ABOUT HERE]}

The final estimation stage involves estimating structural demand parameters in Equation (9) by fixed effects linear regression. The results are presented in Table 3, along with OLS and GLS estimates.

\section{[TABLE 3 ABOUT HERE]}

From these estimates, price and income elasticities are easily computed, as well as their standard errors with the Delta method. The price elasticity is equal to -0.8161 (with standard error of 0.0853 ) and the income elasticity is 0.1462 (with standard error of 0.0367 ).

\section{Simulation experiment}

We now turn to our simulation experiment, that is, calibrating the optimal tariff designed in section 3 with the parameter estimates obtained in section 4. As mentioned before, a natural choice for the agent's type is the households' disposable income with the implicit assumption that the demand for water is increasing in this variable. We first derive the expression of the optimal nonlinear pricing rule when calibrated in the Côte d'Ivoire case. The implementation of this optimal tariff is then simulated with various discretized versions of the tariff, allowing the number of blocks and their bounds to vary.

\subsection{Optimal nonlinear pricing}

The system of nonlinear equations (5) to (8) is used to derive price $p_{\min }$ for the upper bound $q_{\text {min }}$ of the initial (social) pricing block, as well as the nonlinear pricing rule $p(q)$ for water volumes beyond $q_{\text {min }}$. The solution will depend on the parameters of elasticity of demand, 
marginal production cost, statistical distribution of household, and the Ramsey number. The elasticity parameters can be inferred from the estimation step, as follows: the elasticity of demand with respect to the fixed fee, $\varepsilon_{T}^{Q}$, is directly related to the generalized demand function in (3), and is equal to the income elasticity with the opposite sign. $\varepsilon_{T}^{Q}$ is, therefore, computed as $\left.\hat{\beta}_{2} \times T / q\right)$. Also, we compute the price elasticity $\varepsilon_{p}^{Q}$ by using demand estimates, that is, $\varepsilon_{p}^{Q}=\hat{\beta}_{1} \times P / q$.

The marginal cost function $c(q)$ is estimated from an additional data set obtained from SODECI for the same local communities over the same period of time (Diakité and Thomas, $2005)^{22}$. The water supply cost is specified as a translog flexible form depending on output level and input unit prices; and is estimated by imposing the usual homogeneity and symmetry restrictions. The marginal cost is then a nonlinear function of output, which is approximated by a linear regression to a polynomial of degree three: $c(q)=1141.17-$ $11.58 q+0.0375 q^{2}-3.5 \times 10^{-6} q^{3}$.

The density function of the household income is assumed to be Normal $N\left(\mu, \sigma^{2}\right)$. After rescaling the community-specific average household income (in FCFA) by a factor of $10^{5}$, we obtain $\mu=25.87$ and $\sigma=10.86 .^{23}$

Finally, the Ramsey number is not identified and we arbitrarily set $\lambda=1$, which gives $\alpha=0.5 .^{24}$

The computation of welfare changes involves the master profile function defined in Equation (3). This profile can be defined as $Q(P, p, q)=1-\operatorname{prob}[\theta<\theta(P, p, q)]=1-F[\theta(P, p, q))]$ such that $p=\partial U(q, \theta) / \partial q$ or, equivalently, $q=q(p, \theta)$, and with the condition that $U(q, \theta)-P \geq 0$. Using the linear demand specification, the condition $p(q, \theta) \geq p$ for the agent with type $\widehat{\theta}$ is : $\widehat{\theta}=\left(q-\beta_{0}+\beta_{1} p-\delta Z\right) / \beta_{2}$, with the inverse demand function

\footnotetext{
${ }^{22} \mathrm{An}$ initial solution for the optimal tariff was obtained under the assumption of constant marginal cost, however, this assumption was abandoned as it was rejected by the data.

${ }^{23} \mathrm{We}$ also experimented with an exponential distribution for the household income. The resulting optimal price schedule was very similar in shape.

${ }^{24}$ One feature of developing countries is the high opportunity cost of public funds. Many studies confirm that this cost is higher there than in developed countries. It is typically estimated to lie between 1 and 3 , see Laffont $(1996,1999)$.
} 
$p(q, \theta)=\left(\beta_{0}+\beta_{2} \theta-q+\delta Z\right) / \beta_{1}$.

The integral condition defining the master profile function has, in its general form, an infinite upper bound. For the linear demand it is necessary to restrict the admissible values of demand over the positive domain. This implies that $q>0 \Leftrightarrow p<\widehat{p}=\left(\beta_{0}+\beta_{2} \theta+\delta Z\right) / \beta_{1}$. Replacing the upper bound of the integral by $\widehat{p}$ and integrating over the domain of $p$, we have the conditions defining the generalized demand function as follows: $\theta \geq\left(\beta_{1} p+q-\beta_{0}-\delta Z\right) / \beta_{2}$ and $q^{2} / 2 \beta_{1}-p \cdot q-T \geq 0$.

The profile function is easily integrated numerically over the domain of $q$ and/or $p$ and $T$, for computing any component of (consumer or producer) surplus.

The optimal tariff is finally obtained as follows. From Equation (7), we have that $p_{\min }=$ $P_{\text {min }} / q_{\text {min }}$. Replacing the elasticity $\varepsilon_{T}^{Q}$ by its expression above, we obtain

$$
P_{\min }=c\left(q_{\min }\right) \cdot q_{\min }+\frac{\alpha}{\beta_{2}} q_{\min }
$$

so that

$$
p_{\text {min }}=c\left(q_{\text {min }}\right)+\frac{\alpha}{\beta_{2}} .
$$

We then solve for $q_{\min }$ in Equation (5), which reduces to

$$
p_{\text {min }}-c\left(q_{\text {min }}\right)=\alpha q_{\min }\left[f(\widehat{\theta}) \frac{\beta_{1}}{\beta_{2}}\right], \text { where } \widehat{\theta}=\frac{\beta_{1} p_{\min }+q_{\min }-\beta_{0}-\delta Z}{\beta_{2}} .
$$

By replacing the marginal $p$ by the solution for $p_{\min }$, we obtain

$$
1=\beta_{1} q_{\min } f\left[\frac{\beta_{1}\left[c\left(q_{\min }\right)+\alpha / \beta_{2}\right]+q_{\min }-\beta_{0}-\delta Z}{\beta_{2}}\right],
$$

where $f$ is the density function of $\theta$.

Substituting the solution for $q_{\min }$ in Equation (14), we obtain the value of the fixed fee, $P_{\text {min }}$. Finally, the nonlinear price $p(q)$ can be computed from condition (8) as the solution to

$$
p(q)=c(q)+\alpha \frac{\beta_{1}}{\beta_{2}} q f\left[\frac{\beta_{1} p(q)+q-\beta_{0}-\delta Z}{\beta_{2}}\right] .
$$

The nonlinear equation above is solved for $p(q)$ using a numerical root-finding algorithm over a grid of 100 points for consumption $q \in\left[q_{\min }, q_{\max }\right]$. The resulting nonlinear tariff is 
presented in Figure 1. The optimal first ("social") block is found to be between 0 and $q_{\min }$ at $106 \mathrm{~m}^{3}$ /year. Up to $q_{\text {min }}$, households pay a fixed charge $T_{\min }$ (equal to $P_{\min }$ ) that is $P_{\text {min }}=T_{\text {min }}$ estimated at 66.24 USD $/$ year. $^{25}$

The monopoly pricing rule applies for volumes higher than $106 \mathrm{~m}^{3} /$ year. On the decreasing part of the tariff - up to $230 \mathrm{~m}^{3}$ /year - this pricing rule starts with a minimum value of $p\left(q_{\min }\right)$ at $0.67 \mathrm{USD} / \mathrm{m}^{3}$. The optimal marginal price is increasing between 230 and 500 $\mathrm{m}^{3} /$ year, and beyond $500 \mathrm{~m}^{3} /$ year, it is again decreasing. This non-monotonic pattern is mainly due to the marginal cost estimate, which is approximated by a polynomial of order 3. For a typical household, water consumption is less than $200 \mathrm{~m}^{3}$ per year, and therefore it would face a decreasing tariff.

\section{[FIGURE 1 ABOUT HERE]}

The optimal value for $p_{\min }$ is between 0.50 and 0.79 USD, the actual marginal prices for the first and the second pricing block respectively. The total fixed fee in our experiment is estimated at 16.56 USD, a value higher than the actual fixed payment of $4.02 \mathrm{USD} /$ year for the first block in the existing pricing rule. Further, the optimal social consumption threshold in our case is substantially higher than the level observed in Côte d'Ivoire (106 $\mathrm{m}^{3}$ /year versus $36 \mathrm{~m}^{3}$ /year).

Although our simulated pair $\left(p_{\min }, q_{\min }\right)$ departs from the existing one, however it embodies some social considerations as, in the absence of the "social" constraint imposed on the public decision-maker problem, the initial water volumes would have been charged at marginal prices between 0.67 and 2.46 USD $/ \mathrm{m}^{3}$. Moreover, $q_{\min }$ at $106 \mathrm{~m}^{3} /$ year matches the standard recommendations of the United Nations in terms of basic needs for a 6.5-person household.

\footnotetext{
${ }^{25}$ or an equivalent marginal price of $p_{\min }=66.24 / 106=0.62 \mathrm{USD} / \mathrm{m}^{3}$.
} 


\subsection{Implementation : the multiblock tariff}

To make the optimal tariff operational while preserving its main optimality features, we consider a discrete version of the optimal nonlinear pricing rule in the form of a multi-block tariff. The latter is designed to share the features of the optimal tariff, namely, universal service obligations for low annual water consumption and an efficient monopoly pricing for high annual water consumption. Note that in the optimal pricing design, we only need to discretize the monopoly pricing expression as the initial block is already obtained above.

In making approximations to the optimal water tariffs, we consider two different tradeoffs that a public decision-maker may face. The first one is between simplicity of the tariff and its optimality. It is well known from the empirical literature on water demand that the effectiveness of price as a signal on the resource is better achieved through the tariffs that are easily read by customers (monotonic price rates, limited number of pricing blocks). The second trade-off is between optimality and equity of the water tariff. By modifying the structure of the tariff, and possibly, departing from the optimal nonlinear one, it may be possible to increase consumer welfare. To evaluate the impact on welfare of preferring the tariff simplicity to its optimality, or equity to optimality, we compare four different water tariffs.

Tariff 1. This is the existing one in Côte d'Ivoire, with an increasing block structure and three block rates.

Tariff 2. Here we favor the tariff simplicity rather than its optimality, by designing tariff blocks that are closest to the existing tariff, that has an increasing block rate structure. Imposing a monotonic price schedule is very similar to the "ironing" procedure in Wilson (1993) that consists in flattening the pricing rule so that the optimality condition is satisfied on average. Tariff 2 only consists of three blocks, the first one being the "social" block obtained from the nonlinear problem of Section 3. As detailed above, households pay only a fixed fee $P_{\text {min }}^{*}$ of 16.56 USD / quarter for consumption volumes up to $q_{\text {min }}^{*}$ at $106 \mathrm{~m}^{3} /$ year which amounts to charging $p_{1}$ equal to $0.62 \mathrm{USD} / \mathrm{m}^{3}$. The second block is designed to impose a non-decreasing block rate structure, and it ranges from $106 \mathrm{~m}^{3}$ to $365 \mathrm{~m}^{3}$, the 
volume for which the vertical line $p_{2}\left(=p\left(q_{\text {min }}\right)\right)$ at 0.67 USD $/ m^{3}$ cuts the optimal price curve. Between 106 and $365 \mathrm{~m}^{3}$, the second block rate is simply $p_{2}\left(=p\left(q_{\text {min }}\right)\right)$ equal to 0.67 USD $/ \mathrm{m}^{3}$. For the last block, beyond $365 \mathrm{~m}^{3}$ /year, we set the maximum unit rate $p_{3}(=p(500))$ at $0.77 \mathrm{USD} / \mathrm{m}^{3}$. Note that Tariff 2 is rather similar to Tariff 1 in terms of the second block rate $\left(0.77 \mathrm{USD} / \mathrm{m}^{3}\right.$ versus $\left.0.79 \mathrm{USD} / \mathrm{m}^{3}\right)$, and in terms of the third block upper bound (365 $\mathrm{m}^{3}$ /year in both cases).

Tariff 3. Contrary to Tariff 2, we favor optimality over the tariff simplicity, although the number of block rates will be limited. More precisely, the non-decreasing condition is relaxed, so as to correspond more closely to the optimal non linear pricing structure. The first block of Tariff 3 is the predetermined social block for volumes below $106 \mathrm{~m}^{3} /$ year, as under Tariff 2. As the optimal pricing rule is decreasing on the interval $[106,230] \mathrm{m}^{3}$, and then increasing for volumes above $230 \mathrm{~m}^{3}$, we discretize the optimal tariff by considering two blocks in the decreasing part and one block in the increasing part of the tariff. The second block of Tariff 3 is from 106 to $190 \mathrm{~m}^{3}$ /year and the unit rate for this block is simply determined by the monopoly pricing rule applied to the volume $q_{\min }$ of $106 \mathrm{~m}^{3}$ /year, that is, $p_{2}\left(=p\left(q_{\text {min }}\right)\right)$ is 0.67 USD $/ m^{3}$. The third block corresponds to volumes between 190 and $230 \mathrm{~m}^{3}$ /year, and its unit rate is computed as for block 2 , that is, $p_{3}(=p(230))$ is equal to $0.10 \mathrm{USD} / \mathrm{m}^{3}$. The lower bound of the third block is determined arbitrarily, with the objective to keep it sufficiently small due to the corresponding low value for the marginal price. On the increasing part of the tariff, for volumes above $230 \mathrm{~m}^{3}$ / year, we consider only one block and set the marginal price at its highest value possible, that is $p_{4}(=p(500))$ is equal to $0.77 \mathrm{USD} / \mathrm{m}^{3}$.

Tariff 4. This tariff is an extension of Tariff 3. It is identical to Tariff 3 up to 230 $\mathrm{m}^{3} /$ year, and has two additional pricing blocks in the high-volume region (i.e., we consider three blocks instead of one). With this tariff, we are able to evaluate the impact on social welfare of increasing the number of blocks in the water tariff, that is, when the degree of discretization increases. Indeed, Wilson (1993) shows that when the number of blocks tends to infinity, the multiple-block tariff converges to the optimal nonlinear pricing schedule $p(q)$. 
Hence, Tariff 4 allows one to evaluate the trade-off between optimality (better approximating the optimal nonlinear tariff) and equity (the impact on welfare of increasing the number of blocks).

\section{[TABLE 4 ABOUT HERE]}

Table 4 presents the block prices and bounds of the four tariffs. Except for the initial consumption block, all unit rates in Tariff 1 (the existing tariff) are above the rates of our proposed approximations to the optimal nonlinear pricing rule. This is particularly true for consumption levels between 190 and $230 \mathrm{~m}^{3}$ /year, where actual rates are almost twice the value of Tariff 1 rates between 364 and $460 \mathrm{~m}^{3}$ (1.26 USD compared to 0.69 USD). Our approximated multiblock tariffs always have unit price rates above the marginal cost, which is in line with the Feldstein pricing rule discussed in Section 2.1. According to this policy, setting unit rates systematically above marginal cost is a way to reduce the level of the fixed charge. As mentioned in Section 2.3, Ivorian urban water utilities set a single fixed charge: the connection fee, which is paid once and for all (and whose impact on the household income is expected to be smoothed over a long period of time). Our approximation to the optimal nonlinear pricing rule includes a fixed charge in the initial block (as long as there is a strictly positive consumption level) which is higher than the existing one. Therefore, the approximation to the optimal pricing rule tends to reduce inefficiency of the Feldstein pricing rule, by pushing back unit rates in upper blocks toward the marginal cost, and by increasing the fixed charge contained in the initial block.

\subsection{Welfare comparisons}

Our strategy here is to evaluate social welfare associated with the existing water tariff (Tariff 1), and to perform welfare comparisons with our proposed tariffs (Tariffs 2 to 4). We distinguish between the analysis for a representative household (irrespective of his/her income), and a "poor" household (to be defined below). 


\section{Welfare computations for a representative household}

We calculate the change in consumer welfare from the Marshallian consumer surplus for a representative household in each local community (see the Appendix). ${ }^{26}$ Consumer surplus variation $(C S V)$ is defined as the average amount each household would save every year if the existing tariff (Tariff 1) is replaced by a proposed (simulated) tariff. Producer surplus variation $(P S V)$ is the average annual loss per household the water operator would incur by switching from Tariff 1 to a simulated tariff (Tariff 2, 3 or 4 ). Social welfare variation $(W V)$ is the average gain (or loss) per household for the society as a whole (represented here by the representative consumer and the water operator). The welfare changes in relative terms are obtained by dividing $C S V$ and $P S V$ by the average water expenditure of the representative (average) household.

The welfare measures are computed for the country as a whole, using the sample-based empirical distribution of income and proportions of water users in the different price blocks for the full sample. If heterogeneity in operating conditions ${ }^{27}$ and in socio-demographic characteristics of households throughout the country is likely to be significant, computing such welfare variations at the regional level may be more interesting. To this end, we also compute consumer and producer surpluses for each region, by using region-specific household income distribution (mean and standard deviation for a Normal distribution) to calibrate the optimal pricing rule. ${ }^{28}$

\section{[TABLE 5 ABOUT HERE]}

\footnotetext{
${ }^{26}$ While commonly adopted in applied welfare studies, the welfare change for a heterogeneous population is not perfectly captured by the Marshallian consumer surplus, and an exact measure would require the Hicksian demand curve. However, in the instance where only one price changes, Willig (1976) and Hausman (1981) show that it is possible to compute consistent welfare changes using the Marshallian consumer surplus.

${ }^{27}$ Even though SODECI is the major water operator in Côte d'Ivoire, each local community considered here has its own production and distribution networks, and those communities are grouped into 10 Regional Water Districts (DR, Directions Régionales).

${ }^{28}$ Regions are the following: Southwest, Korhogo, Daloa, Bouak, Basse Cote, Abengourou, Yamoussoukro, Man, Abidjan North, Abidjan South.
} 
The results are presented in Table $5 .^{29}$ Columns 3 to 5 of Table 5 report the relative welfare changes associated with the switch from the existing tariff to Tariff 2,3 and 4 respectively, for each of the 10 regions, and the entire country. They are in the same range as those obtained in Garcia and Reynaud (2004) but contrast with those of Swallow and Martin (1988) and Renzetti (1992). ${ }^{30}$

For the country as a whole (last row of Table 5), the change in social welfare from switching to a proposed tariff is positive; however, there are significant differences across regions. While most regions would gain from moving to Tariff 2, 3 or 4 (with a somewhat limited gain for Abidjan North), Basse Cote and Abidjan-South regions would experience a loss in social welfare. This result illustrates the need to account for heterogeneity in social welfare variation at the regional level, when evaluating the implementation of the optimal water pricing policies in countries like Côte d'Ivoire. The existing pricing policy is based on a single (national) price system, which implies that there exist cross subsidies between regions (in addition to the usual cross-subsidy mechanism between users in different block, as implied by the block-rate price rule). Indeed, the city of Abidjan (North and South) benefits from favorable hydrological conditions, and water production is relatively less costly there (groundwater pumping, no filtration treatment). Moreover, the size and density of the population (more than 4 million inhabitants and about 45,000 inhabitants per square kilometer) allow to keep the water supply and customer service costs at a relatively lower level than in other Ivorian cities. The city of Abidjan represents more than 50 percent of all customers, about 60 percent of total billed volumes, 50 percent of expenditures and 60 percent of products (sales) in the water department of SODECI (Collignon, 2002). Therefore, a homogeneous water tariff for the entire market of the SODECI concession seems to generate a de facto subsidy, essentially financed by Abidjan residential customers for the benefit of customers from other local communities in Côte d'Ivoire.

The evaluation of welfare changes associated with different price policies (say, Tariff $k$

\footnotetext{
${ }^{29}$ More detailed tables are omitted due to limited space, and are available from the authors upon request.

${ }^{30}$ Garcia-Reynaud, Swallow-Martin and Renzetti found a 0.4, 2 and 4 percent increase in welfare respectively.
} 
vs. Tariff $k^{\prime}$ ) is made possible by simply comparing welfare change from Tariff 1 to Tariff $k$ with the change generated by the move from Tariff 1 to Tariff $k^{\prime}$. The optimality gain (or equivalently, the loss in the tariff simplicity) generated by the move from Tariff 2 to Tariff 3 or 4 ultimately leads to a slight increase in the total welfare. Remember that Tariff 2 is much closer to the existing one than Tariffs 3 and 4, which are not restricted to be of the increasing-block type. The optimality gain generated by the move from Tariff 3 to Tariff 4 is associated with a decrease in total welfare, hence confirming the existence of a tradeoff between equity and efficiency. Moreover, surplus changes generated by these two tariffs remain intimately related to the choice of pricing block bounds and corresponding marginal prices.

Our results reveal that the existing pricing policy leads to a moderate social welfare gain compared to approximations to the optimal tariff with the same number of blocks (Tariff 2). Based on our welfare computations, the optimal pricing policy would be to keep the existing tariff (Tariff 1) for Abidjan (North and South) and Basse Cote regions, however, to implement the approximated optimal Tariff 4 in all other regions of the country (because it is closest to the optimal pricing rule). This is confirmed by the fact that in 2001 the budget of a large majority of water services (except Abidjan) were actually in deficit.

\section{Welfare analysis for a "poor" household}

Since the objective of the water price policy is to increase water consumption by poorer households while at the same time accounting for the operator benefit, it is necessary to analyze the impact of our simulated tariffs on the welfare of these households. The individual level analysis is not possible due to availability of only aggregate data, and we cannot adopt a definition of poverty based on observed individual income. However, it seems reasonable to assume that poor households that are connected to the water network will have their consumption level in the first pricing block. We therefore define as "poor" a household whose water consumption is below the upper bound of the social pricing block. By doing so, the welfare comparison can be simply made by comparing the water bills a household would 
pay when its consumption lies in the social pricing block, given the existing or alternative tariffs. As our simulated Tariffs 2, 3 and 4 share the same first ("social") block, we conduct a simulation experiment at the regional level to compare the existing tariff (Tariff 1) with any simulated tariff, on the basis of the social block only.

The region-specific empirical distribution of the household income is used to compute the optimal first block for each region. The right-hand side of Table 5 reports the marginal price $p_{\text {min }}$, the associated upper bound of the simulated social pricing block, $q_{\min }$ (in $\mathrm{m}^{3} /$ year), the welfare variation for the representative poor household (denoted by WLoss) and the equivalent bill, BillEq. The latter corresponds to the bill a poor household would pay for a volume corresponding to the (optimal) first block of the simulated tariff if it were charged at the existing price.

We note a negative correlation between the average income $\mu$ and $q_{\text {min }}$, while $p_{\text {min }}$ is rather stable across regions. This relationship seems to indicate that the local communities with a higher proportion of poor households ( $\mu$ small) are those that require a higher volume of water charged at the "social" rate corresponding to the first block.

At the national level, we obtain $q_{\min }$ equal to $106 \mathrm{~m}^{3} /$ year with a marginal price $p_{\min }$ at $0.62 \mathrm{USD} / \mathrm{m}^{3}$. Under the existing water tariff, we have $q_{\min }$ at $76 \mathrm{~m}^{3} /$ year and $p_{\min }$ at 0.50 $\mathrm{USD} / \mathrm{m}^{3}$ respectively. Therefore, a household whose consumption is $106 \mathrm{~m}^{3}$ /year would pay, according to the simulated tariff, a total water bill of $T_{m i n}$ equal to $66.24 \mathrm{USD} /$ year. ${ }^{31}$ The same water consumption under the current tariff would cost the household BillEq of 61.65 USD / year. ${ }^{32}$ It seems that the poor household would pay slightly more with the simulated tariff than with the existing one, with a welfare change of $\left(B i l l E q-T_{\min }\right)$ at -4.59 USD a year.

This welfare loss for consumers from moving from Tariff 1 to any simulated tariff with an optimal first block is, however, very limited when compared to the direct application of the nonlinear pricing rule over the whole range of water volumes. Imposing the first block with a flat rate is strongly in favor of poor households, who would pay much more for the first

\footnotetext{
${ }^{31} 106 \times 0.62=66.24$.

${ }^{32} 18.10+(76-36) \times 0.50+(106-76) \times 0.79=61.65$.
} 
cubic meters if the nonlinear pricing rule were applied for those volumes. This is because the optimal pricing rule is decreasing in the range of consumption that is concerned with the social pricing policy. To impose the optimal tariff that has the "social" first block yields a gain of about 90 USD a year to the representative consumer.

The fact that poor households benefit from the existing tariff as compared to the simulated one suggests that introducing a charge-free consumption volume in the simulated tariffs we consider may be an interesting option (see Gomez-Lobo and D. Contreras, 2000). The "social" volume would simply be equivalent to the loss to households due to the new water tariff. In our case, the representative poor household would be offered at least $8 \mathrm{~m}^{3} /$ year $^{33}$ so as to make the household indifferent between the actual and the simulated tariff. Although the consumption of the household would be $106 \mathrm{~m}^{3}$ /year, it would only be charged $98 \mathrm{~m}^{3}$ /year. ${ }^{34}$

To compensate for the loss to the water service operator if water volumes are supplied free of charge, several alternative tariff policies may be considered. More wealthy consumers - whose consumption is above $190 \mathrm{~m}^{3} /$ year in our experiment - may be excluded from the benefit of the social pricing block. At their consumption level they would pay the simulated optimal price between 0.67 and $2.46 \mathrm{USD} / \mathrm{m}^{3}$. The proposed tariff would then take the form of a menu of tariffs according to the household type as follows:

Poor households (less than $106 \mathrm{~m}^{3}$ /year )

$$
\left\{\begin{array}{l}
\text { Simulated tariffs } \\
+ \text { lump sum consumption depending on welfare loss }
\end{array}\right.
$$

Medium-income households (between 106 and $190 \mathrm{~m}^{3} /$ year)

Simulated tariffs

Well-off households (more than $190 \mathrm{~m}^{3} /$ year )

$$
\left\{\begin{array}{l}
\text { Marginal price between } 0.67 \text { and } 2.46 \mathrm{USD} / \mathrm{m}^{3} \text { below } 106 \mathrm{~m}^{3} / \text { year } \\
\text { Simulated tariffs above } 106 \mathrm{~m}^{3} \text { year. }
\end{array}\right.
$$

In sum, the combination of the welfare analysis at the representative household level on

\footnotetext{
${ }^{33} 2067 / 292 \approx 8$.

${ }^{34} 106-8=98$.
} 
one hand, and at the poor household on the other, clearly reveals that the optimal tariff policy, that includes social objectives as well as accounting for the operator profit, cannot be achieved using a uniform price policy (for the whole concession market and all households). Instead, along the lines of the region-specific tariffs, price schemes should incorporate a menu of tariffs based on actual water consumption by the households.

\section{Conclusion}

This paper has tried to address the problem of the social water pricing in developing countries, where a general pricing policy is an increasing block tariff with a reduced-rate initial block corresponding to basic needs. The main objective of the paper has been the design of the optimal nonlinear tariff from the public regulator's perspective where water is supplied by a private operator facing heterogeneous consumers. Using Wilson's (1993) definition of the generalized demand profile, we propose an optimal pricing rule that combines both equity and efficiency considerations. The resulting tariff entails a fixed fee for the first block of the tariff, presumably dedicated to low-income households, and a nonlinear pricing rule for higher water volumes.

The optimal pricing rule is calibrated using econometric estimates of residential water demand in Côte d'Ivoire, accounting for endogeneity of price as an explanatory variable, and for the fact that the existing tariff has several price rates. Several approximations to the optimal tariff are computed in the form of multiblock tariffs. The impact on welfare of favoring the tariff simplicity to imposing an increasing block rate structure is then evaluated. The results are compared to the existing, increasing-block tariff water pricing in Côte d'Ivoire, and welfare change calculations are performed.

Our results enable us to draw two conclusions. First, the homogeneous water price system over the entire market of the concession is not optimal and can be improved by using essentially the same tariff structure as the existing one. However, total welfare changes are not expected to be large, as producer losses almost compensate for gains in the consumer 
welfare. Second, a better pricing system can be obtained by keeping the existing tariffs in Abidjan and Basse Cote $^{35}$ and adopting our proposed tariffs in the other regions. Moreover, the welfare analysis conducted for poor households reveals the need for classifying households in different categories within the same community, as well as proposing a menu of tariffs. Such a menu - derived from our simulated optimal tariffs - would then allow to improve the trade off between social objectives on one hand, and the operator financial outlook on the other.

\footnotetext{
${ }^{35}$ a region very close to Abidjan
} 


\section{References}

[1] Baumol, W.J. (1987). Ramsey pricing. In The New Palgrave, J. Eatwell, M. Milgate and P. Newman (eds.), vol IV, 49-51. Macmillan Press Ltd., London.

[2] Boland, J.J. and D. Whittington (2000). The political economy of water tariff design in developing countries: Increasing block tariffs versus uniform price with rebate. In The political economy of water pricing reforms, Ariel Dinar (ed.), pp. 215-235. Oxford University Press, Oxford.

[3] Brown S. and D. Sibley (1986). The Theory of Public Utility Pricing, Cambridge University Press.

[4] Burtless, G. and J. Hausman, (1978). The Effect of Taxation on Labor Supply: Evaluating the Gary Negative Income Tax Experiment. Journal of Political Economy 86, 1103-1130.

[5] Chicoine, D., S. Deller, and G. Ramamurthy (1986). Water Demand Estimation Under Block Rate Pricing : A Simultaneous Equation Approach. Water Resources Research $22,859-863$.

[6] Collignon, B. (2002). Urban Water Supply Innovations in Côte d'lvoire: How CrossSubsidies Help the Poor. Nairobi: Water and Sanitation Program - Africa, 2002.

[7] Collignon, B., R. Taisne, and J.-M. S. Kouadio (2000). Water and Sanitation for the Urban Poor in Côte d'Ivoire. Nairobi: Water and Sanitation Program - Africa, 2002.

[8] Corral, L., A. Fischer, and N. Hatch (1998). Price and Non-Price Influences on Water Conservation: An Econometric Model of Aggregate Demand under Non Linear Budget Constraint. Working Paper No 881, Department of Agricultural and Resource Economics and Policy, University of California at Berkeley. 
[9] Diakité, D. and A. Thomas (2005). Structure des Coûts d'Alimentation en Eau Potable : Une Application aux Données des Centres de Production Ivoiriens. Gremaq Working Paper, University of Toulouse.

[10] Diakité, D. and A. Thomas (2006). La Demande d'Eau à Usage Résidentiel en Côte d'Ivoire : Une Analyse Econométrique sur Données de Panel. Gremaq Working Paper, University of Toulouse.

[11] Garcia, S. and A. Reynaud (2004). Estimating the benefits of Efficient Water Pricing in France. Resource and Energy Economics 26, 1-25.

[12] Gleick, P.H. (1996). Basic water requirements for human activities: Meeting human needs. Water International 21, 83-92.

[13] Gomez-Lobo, A. and D. Contreras (2000). Water subsidy policies: A comparison of the Chilean and Colombian schemes. The World Bank Economic Review 17, 391-407.

[14] Hausman, J.A. (1981). Exact Consumer's Surplus and Deadweight Loss. American Economic Review 71, 662-676.

[15] Hewitt, J. and W. Hanemann (1995). A Discrete/continuous Choice Approach to Residential Water Demand under Block Rate Pricing. Land Economics 71, 173-192.

[16] Laffont, J.J.(1999). Competition Information and Development. Annual World Bank Conference on Development Economics 1998, The World Bank, Washington D.C.

[17] Laffont, J.J.( 1996). Regulation, Privatisation and Incentives in Developing Countries. Current Issues in Economic Development, Oxford University Press, Oxford.

[18] Laffont, J.J. and J. Tirole (2000). Competition on telecommunications. MIT Press, Cambridge, MA.

[19] Laffont, J.-J. and J. Tirole (1993). A Theory of Incentives in Procurement and Regulation. MIT Press, Cambridge. 
[20] Martinez-Espiñeira, R., (2003). Estimating Water Demand under Increasing Block Tariffs Using Aggregate Data and Proportions of Users per Block. Environmental and Resource Economics 26, 5-23.

[21] Ménard, C., and G. Clarke (2000). Reforming the Water Supply in Abidjan, Côte d'Ivoire : Mild Reform in a Turbulent Environment. Working paper Series 2377, The World Bank, Washington, D.C.

[22] Moffitt, R. (1986). The Econometrics of Piecewise-linear Budget Constraints. Journal of Business and Economic Statistics 4, 317-328.

[23] Moffitt, R. (1990). The Econometrics of Kinked Budget Constraints. Journal of Economic Perspectives 4, 119-139.

[24] Nordin, J. (1976). A Proposed Modification on Taylor's Demand-Supply Analysis: Comment. Bell Journal of Economic Management and Science 7, 719-721.

[25] Prieger, J.E. (1996). Ramsey pricing and competition: the consequences of myopic regulation. Journal of Regulatory Economics 10, 307-321.

[26] Renzetti, S. and J. Kushner (2004). Full cost accounting for water supply and sewage treatment: Concepts and case application. Canadian Water Resources Journal 29, 1322.

[27] Renzetti, S. (2000). An empirical perspective on water pricing reforms. In The political economy of water pricing reforms, Ariel Dinar (ed.), pp. 123-140. Oxford University Press, Oxford.

[28] Renzetti, S. (1992). Evaluating the Welfare Effects of Reforming Municipal Water Prices. Journal of Environment Economics and Management 22, 147-192.

[29] Shefter, J., and E. David (1985). Estimating Residential Water Demand Under Multipart Tariffs Using Aggregate Data. Land Economics 61, 21-33. 
[30] Strand, J., and I. Walker (2005). Water markets and demand in Central America. Environment and Development Economics 10, 313-335.

[31] Swallow, S. and C. Martin (1988). Long Run Price Inflexibility and Efficiency Loss for Municipal Water Supply. Journal of Environmental Economics and Management 15, 233-247.

[32] Willig, R. (1976). Consumer Surplus without Apology. American Economic Review 66, 589-597.

[33] Wilson, R. (1993). Nonlinear Pricing. Oxford University Press, Oxford. 


\section{Appendix}

\section{Welfare computations}

Consider a representative household of type $\theta$ facing a tariff system $\widetilde{p}=\left\langle m, p_{i}\right\rangle_{i=1, \ldots, m}$, where $m$ is the number of blocks and $p_{i}$ the marginal price of block $i$. The consumer surplus of such a household can be defined as

$$
U(\widetilde{p}, \theta)=\sum_{i=1}^{m-1} \int_{p_{i}}^{p_{i+1}} \tilde{q}\left(\pi_{i}, \theta, Z\right) d \pi_{i}+\int_{p_{m}}^{\infty} \tilde{q}\left(\pi_{i}, \theta, Z\right) d \pi_{i}
$$

where $\tilde{q}\left(p_{i}, \theta, Z\right)$ is the Marshallian linear demand function in each block. For each tariff system an average price is computed over different blocks as $\left(\bar{p}=\sum_{i=1}^{m} a_{i} p_{i}\right)$, where $a_{i}$ is the proportion (share) of total water charged in block $i$. For the existing tariff, these shares are observed from the data. For our proposed tariffs, they are computed using the income distribution for $\theta$. We have

$$
\operatorname{Prob}[q(\bar{p}, \theta, Z) \leq \bar{x}] \Leftrightarrow \operatorname{Prob}\left[\theta \leq \frac{1}{\beta_{2}}\left(\bar{x}-\beta_{0}+\beta_{1} \bar{p}-\delta Z\right)\right]
$$

where $q(\bar{p}, \theta, Z)$ is the estimated linear aggregate demand function defined in Equation (9), and $\bar{x}$ is the upper bound of different blocks.

The consumer surplus for a representative household then reduces to

$$
U(\bar{p}, \theta)=\int_{\bar{p}}^{\infty} q(\pi, \theta, Z) d \pi .
$$

Letting $\bar{p}_{0}$ and $\bar{p}_{1}$ denote average prices for the existing tariff and the proposed tariff respectively, consumer surplus variation is given by

$$
C S V=\int_{\bar{p}_{0}}^{\bar{p}_{1}} q(\pi, \theta, Z) d \pi .
$$

The water operator faced with a household of type $\theta$ and a price rule $\widetilde{p}=\left\langle m, p_{i}\right\rangle_{i=1, \ldots, m}$ has surplus

$$
P S(\widetilde{p}, \theta)=\sum_{i=1}^{m}\left[p_{i}-c(q)\right] \tilde{q}\left(p_{i}, \theta, Z\right)
$$


where $c(q)$ is the marginal cost of the firm to produce a water quantity $\tilde{q}\left(p_{i}, \theta, Z\right)$. With average price $\bar{p}$ computed as above, the firm surplus becomes $P S(\bar{p}, \theta)=[\bar{p}-c(q)] q(\bar{p}, \theta, Z)$ and producer surplus variation is given by

$$
P S V=\left[\bar{p}_{1}-c(q)\right] q\left(\bar{p}_{1}, \theta, Z\right)-\left[\bar{p}_{0}-c(q)\right] q\left(\bar{p}_{0}, \theta, Z\right)
$$

Finally, the total welfare variation is $W V=C S V+P S V$. 
Table 1: Descriptive statistics on the sample, 1998-2002

\begin{tabular}{lrrrr}
\hline \hline Variable & Mean & Std. Dev. & Min. & Max. \\
\hline Water consumption $\left(m^{3}\right)$ & 120.0027 & 43.2310 & 25.3178 & 376.0475 \\
$p_{1}$ (first block, USD $\left./ m^{3}\right)$ & 0.35 & & & \\
$p_{2}$ (second block, USD $\left./ m^{3}\right)$ & 0.54 & & & \\
$p_{3}$ (third block, USD $\left./ m^{3}\right)$ & 0.88 & & & \\
$s_{1}$ (first block) & 0.3443 & 0.0479 & 0.1228 & 0.5250 \\
$s_{2}$ (second block) & 0.5712 & 0.0514 & 0.2002 & 0.7132 \\
$s_{3}$ (third block) & 0.0844 & 0.0404 & 0.0173 & 0.6768 \\
$I$ & 2.6112 & 1.0874 & 0.2525 & 14.4355 \\
UNPAID & 23.1773 & 73.1535 & 0.0070 & 1041.2880 \\
$N E W S U B$ & 0.9183 & 0.1080 & 0.0100 & 0.9998 \\
$A C C E S S$ & 15.5492 & 31.6908 & 0.2660 & 211.3287 \\
$R E T U R N$ & 0.8667 & 0.1193 & 0.3637 & 100.0000 \\
$C U S T$ & 213 & 468 & 1 & 3473 \\
\hline \hline
\end{tabular}

Notes. 780 observations $(N=156, T=5) . p_{j}$ and $s_{j}, j=1,2,3$ denote the marginal price of and the proportion of customers in block $j$ respectively; $I$ : income (in million Francs CFA); UNPAID: unpaid volumes (in 1,000 $\mathrm{m}^{3}$ ); NEWSUB: proportion of subsidized new customers; ACCESS: access to water (in 1,000 individuals); RETURN: network rate of return; CUST: number of customers. 1,000 Franc CFA (FCFA) is about 1.9 USD. 
Table 2: Estimation of the block-choice equations

\begin{tabular}{lrrrr}
\hline \hline & \multicolumn{2}{c}{ Block 2 over Block 1 } & \multicolumn{2}{c}{ Block 3 over Block 1 } \\
\hline Variable & Estimate & t-student & Estimate & t-student \\
\hline$I$ & 2.4519 & 3.25 & 5.7102 & 1.53 \\
PUNPAID & -10.5046 & -2.52 & -10.5046 & -2.52 \\
NEWSUB & -3.3121 & -5.78 & -39.7659 & -10.33 \\
$p / p_{1}$ & -1.3802 & -20.00 & -1.3802 & -20.00 \\
\hline \hline
\end{tabular}

Notes. 780 observations $(N=156, T=5)$. Estimation method: 3SLS with fixed effects. $t$-statistics are computed from robust standard errors. $I$ : income (in million Francs CFA); PUNPAID: proportion of unpaid volumes ; NEWSUB: proportion of subsidized new customers; $p / p_{1}$ : relative water price of block 2 (3) over price of block 1 . Coefficients on the relative price and the proportion of unpaid volumes are constrained to be equal across equations. 
Table 3: Estimation of the aggregate water demand equation

\begin{tabular}{lrrr}
\hline \hline Variable & \multicolumn{3}{c}{ Estimate } \\
& OLS & GLS & Fixed Effects \\
\hline Intercept & 145.0672 & 202.5074 & - \\
& $(5.06)$ & $(9.75)$ & - \\
$p$ (average price) & -3.7639 & -5.6079 & -4.6746 \\
& $(-3.94)$ & $(-8.28)$ & $(-7.57)$ \\
Income $I$ & 1.5527 & 0.9032 & 0.7371 \\
& $(4.13)$ & $(3.79)$ & $(3.58)$ \\
UNPAID (unpaid volumes) & 0.5809 & 0.2082 & 0.2037 \\
& $(1.48)$ & $(1.50)$ & $(1.98)$ \\
ACCESS (access to water) & 0.6767 & 0.5149 & -0.7197 \\
& $(8.11)$ & $(5.52)$ & $(-5.22)$ \\
RETURN (network return) & 0.2847 & 0.4611 & 0.5334 \\
& $(2.63)$ & $(4.92)$ & $(5.57)$ \\
\hline \hline
\end{tabular}

Notes. 780 observations $(N=156, T=5)$. $t$-statistics in parentheses are computed from robust standard errors. Hausman test statistic for comparison between fixed effects and GLS: $\chi^{2}(5)=72.10(0.0000)$. 
Table 4: Existing and simulated water tariffs

\begin{tabular}{|c|c|c|}
\hline Block $\left(m^{3} /\right.$ year $)$ & Designation & $\mathrm{USD} / m^{3}$ \\
\hline \multicolumn{3}{|c|}{ Existing tariff, Tariff 1 (4 blocks) } \\
\hline $0-36$ & Forfait* & - \\
\hline $36-76$ & Social & 0.50 \\
\hline $76-364$ & Residential & 0.79 \\
\hline $364-1200$ & Standard & 1.26 \\
\hline \multicolumn{3}{|c|}{ Tariff 2 (3 blocks) } \\
\hline $0-106$ & First & 0.62 \\
\hline $106-365$ & Second & 0.67 \\
\hline+365 & Third & 0.77 \\
\hline \multicolumn{3}{|c|}{ Tariff 3 (4 blocks) } \\
\hline $0-106$ & First & 0.62 \\
\hline $106-190$ & Second & 0.67 \\
\hline $190-230$ & Third & 0.10 \\
\hline+230 & Fourth & 0.77 \\
\hline \multicolumn{3}{|c|}{ Tariff 4 (6 blocks) } \\
\hline $0-106$ & First & 0.62 \\
\hline $106-190$ & Second & 0.67 \\
\hline $190-230$ & Third & 0.10 \\
\hline $230-350$ & Fourth & 0.39 \\
\hline $350-420$ & Fifth & 0.64 \\
\hline+420 & Sixth & 0.77 \\
\hline
\end{tabular}

${ }^{*}$ Whatever their consumption, households are charged 18.10 USD/year. 
Table 5: Welfare changes - From existing tariff T1 to simulated tariffs T2, T3 and T4

\begin{tabular}{|c|c|c|c|c|c|c|c|c|}
\hline \multirow[t]{2}{*}{ Region } & \multirow[t]{2}{*}{$\begin{array}{l}\text { Household } \\
\text { Income }\end{array}$} & \multicolumn{3}{|c|}{$\begin{array}{c}\text { Welfare change } \\
\qquad(\%)\end{array}$} & \multirow[t]{2}{*}{$p_{\min }$} & \multirow[t]{2}{*}{$q_{\min }$} & \multirow[t]{2}{*}{ WLoss } & \multirow[t]{2}{*}{ BillEq } \\
\hline & & $\mathrm{T} 1 \rightarrow \mathrm{T} 2$ & $\mathrm{~T} 1 \rightarrow \mathrm{T} 3$ & $\mathrm{~T} 1 \rightarrow \mathrm{T} 4$ & & & & \\
\hline Southwest & 26.22 & 3.54 & 4.13 & 3.95 & 0.88 & 84 & -29.23 & 44.47 \\
\hline Korhogo & 23.52 & 3.29 & 3.99 & 3.78 & 0.87 & 85 & -28.60 & 45.25 \\
\hline Daloa & 28.19 & 3.12 & 3.95 & 3.70 & 0.90 & 82 & -30.62 & 42.91 \\
\hline Bouak & 22.07 & 4.28 & 4.84 & 4.67 & 0.87 & 85 & -28.42 & 45.25 \\
\hline Basse Cote & 22.67 & -1.30 & -2.41 & -2.08 & 0.87 & 85 & -28.42 & 45.25 \\
\hline Abengourou & 21.83 & 2.86 & 1.97 & 2.23 & 0.77 & 93 & -20.35 & 51.50 \\
\hline Yamoussoukro & 26.26 & 4.08 & 3.70 & 1.86 & 0.89 & 84 & -29.95 & 44.47 \\
\hline Man & 29.20 & 3.00 & 3.55 & 3.42 & 0.84 & 87 & -26.17 & 46.81 \\
\hline Abidjan-North & 43.12 & 1.24 & 1.77 & 1.59 & 0.98 & 76 & -36.59 & 38.22 \\
\hline Abidjan-South & 45.15 & -2.47 & -2.63 & -2.59 & 0.98 & 76 & -36.59 & 38.22 \\
\hline Whole Abidjan & 43.93 & 0.23 & 0.57 & 0.47 & 0.99 & 76 & -36.92 & 38.22 \\
\hline All regions & 25.87 & 0.99 & 1.23 & 1.16 & 0.62 & 106 & -4.59 & 61.65 \\
\hline
\end{tabular}

Notes. Average income is in 1,000 USD per year. T $k$ stands for Tariff $k$, with $k=1,2,3,4$. $p_{\min }$ (in USD $/ m^{3}$ ) and $q_{\min }$ (in $m^{3}$ ) denote the marginal price and the upper bound of the simulated social block respectively. WLoss (in USD/year) is the (negative) welfare change for a representative poor household. BillEq (in USD/year) denotes the bill a poor household would pay for a volume corresponding to the (optimal) first block of the simulated tariff, if it were charged at the existing price rate. 